\title{
COVID-19 y Digitalización "Improvisada" en Educación Secundaria: Tensiones Emocionales e Identidad Profesional Cuestionada
}

\section{COVID-19 and "Improvised" Digitization in Secondary Education: Emotional Tensions and Challenged Professional Identity}

\author{
Javier Molina-Pérez ${ }^{1, *}$ y Cristina Pulido-Montes ${ }^{2}$ \\ ${ }^{1}$ Universidad de Granada \\ ${ }^{2}$ Universidad de Valencia
}

\section{DESCRIPTORES:}

Covid-19

Digitalización

Docente de secundaria Identidad

Política educacional

\begin{abstract}
RESUMEN:
La investigación trata de comprender cómo está experimentando el profesorado la transformación desde la docencia presencial a la docencia online como consecuencia del COVID-19 y sus implicaciones profesionales y educativas. Se presenta una exploración inicial de un estudio más amplio que utiliza un enfoque metodológico cualitativo. Mediante dieciocho entrevistas semiestructuradas a docentes de Educación Secundaria Obligatoria y Bachillerato de Andalucía se (re)construye la experiencia del profesorado durante la educación remota. Se evidencia la precariedad de las infraestructuras digitales disponibles, la falta de recursos y las limitaciones digitales existentes. Se alerta de las consecuencias educativas en términos de desigualdad para el alumnado y la oportunidad de mercado para el edubisness. Por otro lado, se revela una vivencia angustiada del profesorado ante el abandono percibido por parte de la administración educativa. Se denuncian dificultades ante la urgencia de la respuesta educativa "improvisada" donde el profesorado no cuenta con los recursos, la formación y los medios para poder desarrollarla. Esto ha redundado en tensiones emocionales, malestar docente y procesos de "auto-responsabilización" en el seguimiento educativo del alumnado que han originado desequilibrios en las dimensiones que determinan la identidad profesional del profesorado.
\end{abstract}

\section{KEYWORDS:}

Covid-19

Digitization

Secondary school teacher

Identity

Educational policy

\section{ABSTRACT:}

This research attempts to understand how teachers are experiencing the transformation from face-to-face teaching to online teaching as a consequence of COVID-19 and its professional and educational implications. It presents an initial exploration of a larger study using a qualitative methodological approach. Through eighteen semi-structured interviews with teachers of Compulsory Secondary Education and Baccalaureate in Andalusia, a picture of a teacher's experience of remote education is (re)constructed. The precariousness of the available digital infrastructure, the lack of resources and the existing digital limitations are evident. The educational consequences in terms of inequality for students and the market opportunity for edubisness is also highlighted. On the other hand, it also revealed the anguish experienced by the teachers faced with perceived abandonment by the educational administration. Difficulties were reported in view of the urgency of this "improvised" educational response where teachers do not have the resources, training and means to develop it. This has resulted in emotional tensions, unhappiness amongh teachers and the assumption of responsibility for the educational follow-up of students that have caused imbalances in the dimensions that determine the professional identity of teachers.

CÓMO CITAR:

Molina-Pérez, J. y Pulido-Montes, C. (2021). COVID-19 y digitalización “improvisada” en educación secundaria: Tensiones emocionales e identidad profesional cuestionada. Revista Internacional de Educación para la Justicia Social, 10(1), 181-196. https://doi.org/10.15366/riejs2021.10.1.011

${ }^{*}$ Contacto: javimp@ugr.es

ISSN: 2254-3139

revistas.uam.es/riejs
Recibido: 25 de junio 2020

1a Evaluación: 23 de septiembre 2020

2a Evaluación: 19 de noviembre 2020

Aceptado: 21 de enero 2021 


\section{Antecedentes teóricos: estado de la cuestión y nociones principales}

Las nuevas tecnologías de la información y la comunicación (TIC) irrumpen con fuerza en educación durante la década de los 90 tras la creación de la World Wide Web (Gispert-Pellicer, 1997). Aumentan entonces las tesis sobre el cambio tecnológico necesario e imprescindible de los sistemas educativos para formar al capital intelectual que medirá el crecimiento y competitividad de los países y regiones (Bueno et al., 2008). Por ello, no puede obviarse para el análisis de las implicaciones educativas del COVID-19 el contexto político que orienta las finalidades de los sistemas educativos. La agenda neoliberal se ha extendido por la mayoría de los países a través de prácticas y programas que atienden a transformaciones permanentes caracterizadas por ensamblajes, movilidades y mutaciones para su recontextualización en geografías diversas. En consecuencia, se opta por entender estos procesos como "neoliberalización" para destacar el carácter fluctuante de lo que se ha entendido como "neoliberalismo" (Springer, 2010). Los procesos de neoliberalización han promulgado dos vías de actuación no excluyentes e hibridadas en gran parte de los sistemas educativos. Por un lado, el programa de la Nueva Gestión Pública (NGP), que incorpora a la educación pública los métodos y filosofías de gestión del sector privado (Verger y Normand, 2015). Una agenda compartida por gobiernos de diferente signo ideológico por sus promesas de eficacia, eficiencia y desburocratización. Por otro lado, se han ejecutado nuevos modelos de gobernanza. Los gobiernos no se entienden sin las alianzas con organismos, corporaciones y fundaciones del sector privado (Saura, 2018). Las Asociaciones Público-Privadas (APP) se configuran como nuevo modelo de gobernanza y prestación de servicios. En este caso, es interesante explorar las relaciones de los ejecutivos con el sector privado de la tecnología. Ball y otros (2017) describen cómo las corporaciones y empresas de las TIC han visto en el sector de la educación un nicho de mercado potencial, siendo la industria tecnológica una de las más importantes del edubisness.

Existe una amplia aprobación en señalar que la introducción de la digitalización plantea nuevas demandas sobre el profesorado. Se espera un cambio en sus habilidades, roles e identidad, pasando de ser el detentor del saber a un mediador de la información en los procesos de enseñanza-aprendizaje. Una parte de la literatura se cuestiona si su integración supone relegar al profesorado a un rol residual en detrimento de la inteligencia tecnológica (Bueno et al., 2008). Otra parte de las investigaciones inciden en la dimensión técnica y didáctica de las TIC y se han centrado en analizar prácticas efectivas sobre su integración en el currículum y la incorporación de los diferentes dispositivos en las distintas etapas educativas, como exponen Hinojo-Lucena y otros (2020) en una revisión sobre la producción académica. Sin embargo, corrientes críticas denuncian la vinculación directa establecida entre la integración de las TIC, con la utilización de recursos y plataformas, y la noción de innovación docente (Cornet-Calveras, 2005).

Con las medidas de cierre total o parcial de los centros educativos a nivel global para la contención de la propagación del virus se ha dejado a millones de alumnos y alumnas fuera de las aulas. Esta situación ha llevado a la mayoría de los gobiernos a dar continuidad al derecho a la educación en modalidad remota. En este contexto, 63 millones de docentes se han visto obligados a trabajar desde casa y a reformular su docencia (UNESCO, 2020). Sin embargo, la pandemia del COVID-19 ha puesto de relieve dificultades para materializar con éxito la educación online. La adaptación digital, según los datos cotejados, puede estar encontrando barreras referidas a las deficiencias en las infraestructuras tecnológicas de los hogares, la ausencia de recursos TIC y las brechas digitales del profesorado y del alumnado (Zubillaga y Gortazar, 2020; Comisión Europea, 2019). Esto ha despertado el interés académico y están desarrollándose distintos trabajos que tratan de recoger las percepciones del profesorado durante la educación a distancia, considerando cuestiones como la vivencia emocional, la percepción de apoyo administrativo o la competencia profesional, entre otras (Luengo y Manso, 2020; Trujillo-Sáez et al., 2020).

Es interesante comprobar cómo la literatura académica ha evolucionado desde los posicionamientos funcionalistas, centrados en la relevancia de cuestiones técnicas y didácticas, para destacar el papel de las emociones en el éxito educativo y el desarrollo profesional docente. Esta cuestión es hoy más relevante. La dimensión emocional del trabajo del profesorado se ha revelado como un aspecto fun- 
damental sobre el que estudiar la profesionalidad docente o la solidez de su identidad profesional en un momento de crisis de los sistemas educativos. Pese a la complejidad del macroconcepto de identidad, la diversidad de aproximaciones teóricas y el eclecticismo de su abordaje metodológico, lo cierto es que la noción de identidad no conforma una realidad objetiva, sino una construcción discursiva y psicológica que las personas utilizan para entenderse a sí mismas en relación con el entorno que las circunscribe y bajo relaciones mediadas por determinantes sociales, culturales, personales o profesionales (Bolívar et al., 2014). La falta de certezas que acompaña a la crisis del COVID-19 no solo tiene implicaciones educativas en términos de desigualdad o exclusión. Es imprescindible estudiar su incidencia en la dimensión emocional del profesorado, en su percepción de competencia profesional en escenarios desconocidos, en el reconocimiento y apoyo social e institucional percibido, en la adopción de determinadas actitudes ante la inestable legislación o en su negociación personal en términos de desarrollo profesional. Todas ellas son dimensiones que determinan su identidad profesional (Bolívar, 2006; Molina-Pérez y Luengo, 2020) e interactúan en una geografía personal condicionada por factores biográfico-emocionales, factores relacionados con el contexto educativo y factores vinculados a decisiones políticas (Day, 2018).

Por ello, debido a la relevancia de las cuestiones señaladas, y detectando un vacío en la literatura académica que progresivamente aborda la situación de la educación como consecuencia de la pandemia, se plantean las siguientes preguntas de investigación, centradas en la Comunidad Autónoma de Andalucía (España) y que guían el desarrollo de este trabajo:

- ¿Cómo está viviendo el profesorado la transformación desde la docencia presencial a la docencia online como consecuencia del COVID-19?

- Cuáles son las implicaciones profesionales y educativas de la rápida digitalización de la educación?

- ¿Cómo está viviendo emocionalmente el profesorado la educación remota?

- ¿Se siente el profesorado respaldado, apoyado y reconocido por la administración educativa en el cambio de escenario producido por el COVID-19?

\section{Método}

Las preguntas de investigación determinan el seguimiento de una metodología cualitativa ${ }^{1}$. Se centra la atención en la narrativa para captar las dimensiones humanas que influyen en un contexto de crisis. Se trata, como exponía Giddens (1995), de desarrollar una "genealogía de contexto" para descubrir las relaciones que el sujeto establece con su acción y un espacio-tiempo caracterizado por la educación remota. Las narrativas de los diferentes participantes son un medio para reconstruir las vivencias del profesorado durante la educación a distancia. Este procedimiento determina la utilización de un método inductivo. El análisis individual de las narrativas, previa codificación, sirve para descubrir la vivencia del profesorado durante la crisis sanitaria, en línea con planteamientos metodológicos utilizados con éxito en este ámbito (Bolívar et al., 2014). En consecuencia, se sigue un método de análisis con procedimientos de inducción y comparación al objeto de elaborar un espacio teórico que integre las teorías sustantivas de los participantes con las teorías formales de la literatura académica y las aportaciones propias de los investigadores de acuerdo con las particularidades del contexto de estudio (Glaser y Strauss, 1967). En este apartado, se ha buscado la triangulación de las informaciones recabadas de fuentes primarias con los datos proporcionados por instituciones como la Fundación COTEC, la Comisión Europea y las encuestas realizadas al profesorado español, coordinadas por Luengo y Manso (2020) y Trujillo-Sáez y otros (2020), que consideran las infraes-

1 El trabajo que se presenta forma parte de un proyecto de investigación más amplio que pretende comprender las reconstrucciones de la identidad profesional en un contexto determinado por la gestión empresarial de la educación. Este trabajo presenta resultados preliminares sobre el impacto de la crisis del COVID-19 en las vidas profesionales del profesorado de la enseñanza secundaria de Andalucía. 
tructuras digitales, las competencias del profesorado y las implicaciones emocionales y educativas de la educación online. Un análisis de contenido sobre informes, datos y estadísticas realizado con la finalidad de poner en diálogo los relatos del profesorado con los datos disponibles sobre la influencia del COVID-19 en la educación.

Como instrumento de recogida de información se emplea la entrevista cualitativa con una finalidad hipotético-inductiva para profundizar en las vivencias, creencias, percepciones e interpretaciones del profesorado (Wengraf, 2012). Para este caso se desarrolla una entrevista semiestructurada en profundidad que incorpora aspectos referidos a la influencia del COVID-19 en la identidad profesional del profesorado y las implicaciones socioeducativas. Se profundiza en cuestiones como su autopercepción durante la educación online, las vivencias emocionales, la (in)satisfacción con el apoyo recibido o sus consideraciones sobre las consecuencias socioeducativas de la educación remota. Las entrevistas se han desarrollado entre el 24 de marzo de 2020 y el 10 de junio de 2020.

Se han entrevistado a dieciocho docentes cuya tarea se desarrolla en Institutos de Educación Secundaria, de gestión y titularidad pública, en la Comunidad Autónoma de Andalucía (España). El profesorado entrevistado imparte docencia en Educación Secundaria Obligatoria (E.S.O.) y Bachillerato. La selección de participantes no sigue un criterio de aleatorización ni representatividad y atiende a “casos de interés" definidos por una serie de características para recoger testimonios con diferentes experiencias y perfiles profesionales ${ }^{2}$. Se ha empleado la técnica snowball sampling (Noy, 2008) para acceder a sujetos que reúnen las consideraciones de interés y equilibrar las particularidades respecto a los casos previos. Esto atiende a una búsqueda de "casos discrepantes" y no se plantea con intención de realizar análisis diferenciados o correlación de variables (Krueger y Casey, 2009). De este modo, el trabajo recoge las narrativas de nueve profesoras y nueve profesores, con trayectorias en la docencia comprendidas entre los tres años y los veintiocho años, siendo trece personal funcionario y cinco personal interino que desarrollan su práctica docente en centros urbanos, metropolitanos-semiurbanos y rurales. Atendiendo a las áreas de conocimiento, siete docentes tienen titulaciones referidas a Ciencias Formales o Naturales y once docentes poseen titulaciones de Ciencias Sociales o Humanidades.

Para la gestión de las informaciones y el tratamiento de las narrativas se ha utilizado el software NVivo. Se ha realizado un proceso de codificación inductiva (figura 1 y figura 2) que comienza con una codificación "en vivo" donde se extrae la unidad de significado con valor para los interrogantes propuestos. Se trata de una codificación que sintetiza las narrativas y se define con una nomenclatura que incorpora la idea del participante. El proceso de análisis continúa con una tarea de reorganización de la información que atiende al establecimiento de similitudes, emparejamientos y saturación de los códigos (Charmaz, 2004). La integración de códigos en procedimientos emergentes de "construcción de la teoría" definió las siguientes nueve categorías basadas en las narrativa de los informantes: "digitalización improvisada"; "TIC e implicaciones educativas para profesorado y alumnado"; "innovación docente desde las TIC"; "organismos privados como precursores de digitalización"; "docentes quemados y hastiados"; "malestar docente y tensiones emocionales"; "débil reconocimiento social"; "burocratización, resultados y control docente" y "gestión emocional resiliente como respuesta”.

Estas categorías se desarrollan en los siguientes apartados donde se emplean las narrativas del profesorado al tiempo que se discuten con las interpretaciones de los investigadores y las evidencias de la literatura académica. En el proceso de (re)construcción de las vivencias del profesorado se han diferenciado dos apartados sobre los que organizar los resultados. El primero (figura 1) se centra sobre el impacto de la educación a distancia, la forzada digitalización y las implicaciones socioeducativas que conlleva. El segundo (figura 2) desarrolla las categorías referidas a las vivencias del profesorado, el impacto emocional, la percepción de apoyo, reconocimiento y las estrategias de reconstrucción de su identidad profesional.

2 Profesorado de E.S.O. y Bachillerato de las provincias de Andalucía que no ocupen cargos en la dirección del centro, con distintos años de trayectoria y situación profesional, de diversas áreas de conocimiento e impartiendo docencia en centros ubicados en zonas urbanas, semiurbanas y/o rurales. 
Figura 1

Proceso de análisis de informaciones sobre digitalización e implicaciones educativas

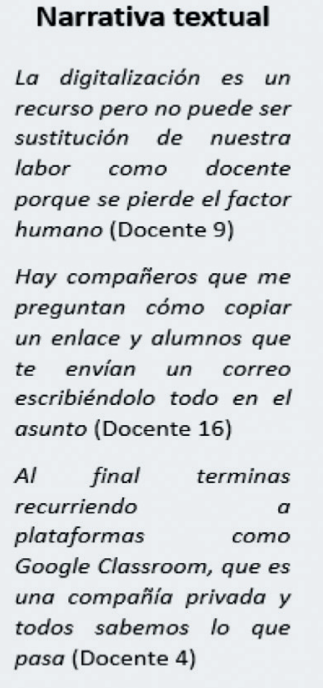

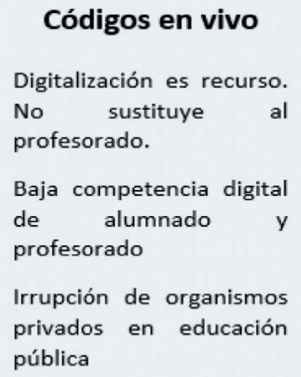

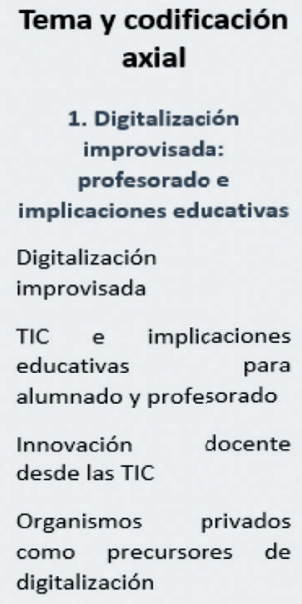

Figura 2

Proceso de análisis de informaciones sobre vivencia del profesorado

\begin{tabular}{|c|c|c|}
\hline Narrativa textual & Códigos en vivo & $\begin{array}{c}\text { Tema y codificación } \\
\text { axial }\end{array}$ \\
\hline $\begin{array}{l}\text { Es una dejación, una falta } \\
\text { de apoyo, un esconderse } \\
\text { en los peores momentos, } \\
\text { brutal (Docente 12) }\end{array}$ & $\begin{array}{l}\text { Falta de apoyo de la } \\
\text { administración } \\
\text { Burocratización y }\end{array}$ & $\begin{array}{c}\text { 2. El rol de la } \\
\text { administración educativa } \\
\text { en la crisis: } \\
\text { cuestionamiento }\end{array}$ \\
\hline $\begin{array}{l}\text { Necesitamos una } \\
\text { legislación que confie } \\
\text { mucho más en los } \\
\text { docentes y que no }\end{array}$ & $\begin{array}{l}\text { sobrelegislación para } \\
\text { controlar al profesorado } \\
\text { No nos sentimos } \\
\text { reconocidos socialmente }\end{array}$ & $\begin{array}{l}\text { docente, tensiones } \\
\text { emocionales y } \\
\text { debilitamiento de la } \\
\text { profesionalidad }\end{array}$ \\
\hline $\begin{array}{l}\text { sobrelegisle para } \\
\text { cargarnos de historias } \\
\text { (Docente 10) }\end{array}$ & $\begin{array}{l}\text { No se considera nuestro } \\
\text { juicio profesional }\end{array}$ & $\begin{array}{l}\text { Docentes quemados y } \\
\text { hastiados }\end{array}$ \\
\hline $\begin{array}{l}\text { Nadie está viendo la } \\
\text { labor de la docencia, }\end{array}$ & $\begin{array}{l}\text { Soy crítico pero el } \\
\text { alumnado es lo primero }\end{array}$ & $\begin{array}{l}\text { Malestar docente y } \\
\text { tensiones emocionales }\end{array}$ \\
\hline $\begin{array}{l}\text { nadie nos va a hacer } \\
\text { mención (Docente } 8 \text { ) }\end{array}$ & $\begin{array}{l}\begin{array}{l}\text { Resiliencia ante la } \\
\text { ambivalencia }\end{array}\end{array}$ & $\begin{array}{l}\text { Débil reconocimiento } \\
\text { social }\end{array}$ \\
\hline $\begin{array}{l}\text { Lo que más me preocupa } \\
\text { es seguir manteniendo la } \\
\text { ilusión. Ser crítico pero }\end{array}$ & & $\begin{array}{l}\text { Burocratización, } \\
\text { resultados y control } \\
\text { docente }\end{array}$ \\
\hline $\begin{array}{l}\text { también } \\
\text { (Docente 1) }\end{array}$ & & $\begin{array}{lr}\text { Gestión } & \text { emocional } \\
\text { "resiliente" } & \text { como } \\
\text { respuesta } & \end{array}$ \\
\hline
\end{tabular}

\section{Resultados}

\subsection{Digitalización improvisada: profesorado e implicaciones educativas}

Aunque la digitalización de los centros educativos y el desarrollo de competencias para integrar las TIC son parte de las agendas globales de reforma educativa desde la década de los 90 del siglo XX (Gispert-Pellicer, 1997), esto no ha supuesto que la cultura de la digitalización, las infraestructuras y las competencias digitales sean una realidad equilibrada que permita desarrollar una respuesta educativa remota. Ni tan siquiera es una propuesta compartida entre el profesorado por diversas casuísticas:

Soy muy crítico con el PRODIG (Programa de Digitalización de centros). Digitalizar a todo el profesorado, a todos los alumnos: ¡no! Yo no voy a digitalizar a un profesor de filosofía ni 
de matemáticas. Que te lo diga yo tiene guasa que soy ingeniero informático y coordinador PRODIG. Tiene que ser un servicio y un recurso al servicio del profesor que lo necesite, pero las directrices que nos dan desde delegación son la leche. Te dicen "el porcentaje de aplicación...” ¿Si es $70 \%$ es bueno y si es 30\% es malo? ¿Ya estás diciendo que el otro \% no es bueno? Son medidas de calidad completamente absurdas. (Docente 1)

Ya desde los últimos lustros del siglo XX la mayor parte del profesorado miraba la introducción de las TIC con recelo y temor a la utilización de dispositivos electrónicos como elementos que pudieran sustituir el trabajo docente (Yanes-González y Area-Moreira,1998). Parece evidente que la pandemia del COVID-19 y el requerimiento inmediato de una educación digitalizada ha alterado las lógicas de trabajo del profesorado de manera forzada. En las narrativas pueden observarse inestabilidades e inseguridades que revelan preocupaciones clásicas en los docentes tras la irrupción de las TIC en educación:

\section{La digitalización es un recurso pero no puede ser sustitución de nuestra labor como docentes porque se pierde el factor humano. Los alumnos deben sentir ese contacto. Es muy importan- te ser muy empático y eso no te lo dan los ordenadores. Que sí, que se digitalicen los centros pero nunca que se sustituyan. (Docente 9)}

La educación telemática y las TIC han sido acogidas socialmente con entusiasmo por sus potencialidades para mejorar la autorregulación del aprendizaje y construir un trabajador competente en organizaciones post-fordistas (Sennett, 2006). Sin embargo, parte del profesorado teme que se consolide una línea discursiva que entienda la educación remota como la única respuesta para garantizar el derecho a la educación. Por ello, en estos momentos de incertidumbre, el profesorado entrevistado vive con inquietud los posicionamientos globales que entienden la crisis sanitaria como una oportunidad para implementar con carácter permanente la docencia online. En momentos de COVID-19 los docentes reivindican la presencialidad segura de los procesos de enseñanza-aprendizaje que ven amenazada. Al tiempo, rechazan una educación que los aísla del contacto inmediato con el alumnado y la falta de cercanía con clases en streaming. Esta cuestión recupera la idea que ya exponía Hargreaves (1996), entendiendo el aula como una isla que permite al profesorado mantener un deseado nivel de intimidad y protección frente a posibles injerencias externas.

Yo en el confinamiento lo estoy pasando mal porque considero que mi trabajo es el contacto con mis alumnos, y eso me lo han quitado. Trabajo, y trabajo más, pero es como si no trabajara, es un trabajo todavía más burocrático porque no puedo dar clase. (Docente 15)

La respuesta telemática como solución para dar continuidad al derecho a la educación abre nuevas brechas que afectan en mayor medida al alumnado más vulnerable. También pone de manifiesto las dificultades que tiene el profesorado con menor alfabetización digital:

Esto está siendo un lío. Ha cogido a muchos profesores con el pie cambiado. Muchos siempre han sido reacios con el tema de lo digital. Hay compañeros que me preguntan cómo copiar un enlace y alumnos que te envían un correo escribiéndolo todo en el asunto. Y eso describe la situación. (Docente 16)

Según el informe realizado por Zubillaga y Gortazar (2020) para la Fundación COTEC a partir del informe PISA (2018), el porcentaje de integración de las TIC en secundaria para el curso 2017/2018 apenas superaba, de media, el 50\%, siendo muy dependiente de la capacitación digital del profesorado. Otros datos proporcionados por la Comisión Europea (2019) en la Second Survey of Schools: ICT in Education del curso 2017/2018 han mostrado que más de la mitad del profesorado de la Unión Europea (UE) encontraba importantes obstáculos para implementar las TIC en las instituciones educativas como consecuencia del número de ordenadores, tablets, velocidad y conexión a internet. Según el estudio coordinado por Luengo y Manso (2020), en el que se han encuestado a 3700 docentes, el $90 \%$ confiesa estar aprendiendo a "innovar" e integrar las TIC de manera autodidacta. Y es que el 33\% del profesorado encuestado no tiene formación digital y el $60 \%$ no ha recibido capacitación en TIC. Esto está motivado por la escasez de plataformas y recursos previos de los que se disponía a nivel de centro (entornos virtuales de aprendizaje o aplicaciones, entre otros). Estas cuestiones explican las dificultades de partida del sistema educativo y la precariedad con la que han afrontado los docentes la digitalización de los procesos de enseñanza-aprendizaje. Datos cuantitativos a los que el profesorado pone voz descubriendo su percepción en este apartado: 
Yo en el aula tengo una pizarra digital que funciona a dias y mis alumnos no se van a llevar sus materiales a la clase, primero porque no tienen y, segundo, porque si todos nos conectamos a la Wifi sería un problema porque te piden la Wifi y no se la podemos dar. Aquí tenemos que dar las gracias al coordinador TIC que se desvive para utilizar ordenadores que tienen muchísimos años y que funcionan de aquella manera. (Docente 6)

Aunque hay diferencias importantes entre países, el informe de la Comisión Europea (2019) señala que más del 50\% del profesorado de la UE considera que existen otras dificultades importantes para implementar pedagógicamente las TIC. Se recogen limitaciones para integrarlas en el currículum, falta de contenidos y materiales adecuados, falta de soporte pedagógico-técnico y falta de habilidades digitales del alumnado y del profesorado. Sin embargo, pese a la evidencia recogida sobre las dificultades que ha experimentado el profesorado para responder a la educación remota, los docentes se sienten interpelados para responder de la mejor manera posible a este desafío educativo. Son varias las narrativas que muestran que, a pesar del carente apoyo pedagógico y tecnológico que reciben, han aplicado nuevas fórmulas y más tiempo del reconocido para tratar de continuar su labor en condiciones no habituales.

Créeme que llevo tres días, aunque esté de vacaciones (Semana Santa), buscando y leyendo herramientas, formas y maneras de intentar garantizar que el alumno no se me desconecte con el teletrabajo. (Docente 7)

Lo cierto es que los relatos de esta investigación evidencian que la digitalización y la disposición de aulas virtuales en los centros no es una realidad generalizada en el contexto andaluz. Contar con estos recursos ante el cierre de los centros facilita la estructuración de las clases, las tareas y la comunicación con el alumnado, sin embargo, el profesorado alerta:

La infraestructura digital de la que disponemos es un caos. A mí ahora solo me funciona el correo. Se ha visto que en la crisis del coronavirus SÉNECA ha estado dos semanas sin funcionary Moodle, que es la plataforma donde podríamos dar clases online y subir materiales, no funcionaba. (Docente 3)

Atendiendo al trabajo de Trujillo-Sáez y otros (2020) la experiencia durante el confinamiento lleva al $76,8 \%$ de los 5000 docentes encuestados a reclamar un aumento de las inversiones en docencia a distancia de cara a próximos cursos. A su vez, el 59\% del profesorado considera necesario invertir en la disponibilidad de plataformas y materiales de aprendizaje en línea adaptados a todo el alumnado. Estas preocupaciones se relacionan con que el profesorado se está viendo obligado a recurrir a plataformas privadas en abierto para poder impartir docencia en streaming o diseñar actividades. A partir de la proliferación y uso de este tipo de plataformas, docentes y académicos han denunciado la utilización de datos mediante algoritmos con fines comerciales (Tett y Hamilton, 2019; Williamson, 2017). Es evidente que, en la era del capitalismo, la crisis surge como oportunidad para ampliar los nichos de mercado y extender el crecimiento de la Industria Global de la Educación (IGE). El negocio de las Edtechs como expertise frente a las instituciones públicas educativas que terminan contratando servicios de manera externalizada son uno de los nichos de mercado que han experimentado un mayor crecimiento dentro de la IGE (Ball et al., 2017). Trabajos como el desarrollado por Saura (2018), proyectan un escenario de APP que, en el seno de la gobernanza, determinan nuevos modelos de gobierno donde la acción de los ejecutivos no se entiende sin alianzas con nuevos modelos de filantropía y corporaciones privadas. A pesar de ello, ante la falta de recursos, el profesorado apuesta por la utilización de las plataformas diseñadas por empresas privadas de fácil uso pese a mostrar reticencias a su aplicación o advertencia de sus implicaciones.

Hay un apartado que no me gusta y es que al final terminas recurriendo a plataformas como Google Classroom, que es una compañía privada y todos sabemos lo que pasa con los algoritmos y cómo copian los recursos y la información para luego ellos generar ese tipo de ofertas también. Y claro, dices, yo me sirvo de ellos pero luego ellos qué van a hacer y cómo pueden llegar a cambiar el modelo educativo porque les sería muy fácil copiar los modelos y vender cursos así. (Docente 4)

Dame medios y dame recursos. ¿Vamos de digital? Pues vamos a digitalizarnos todos, pero no dándoles como hizo la Junta de Andalucía un contrato con una empresa para repartir ordenadores de los que nunca más se supo, eso no es digitalizar, es hacer negocio. (Docente 8) 
Sin restar relevancia a estas cuestiones, es preocupante que una parte mayoritaria del profesorado entrevistado ha destacado una evidente dificultad para el seguimiento de la educación online, especialmente referido al sector más vulnerable del alumnado. Esta consideración es coherente con las aportaciones de Luengo y Manso (2020) donde se identifica que el 30\% de docentes cuenta con dificultades para mantener el seguimiento del proceso educativo del alumnado con índices socioeconómicos más bajos. Esta es una cuestión problemática sobre la que el profesorado entrevistado se ha mostrado preocupado por la incidencia en materia de desigualdad educativa:

\begin{abstract}
Algunos alumnos no te están entregando ejercicios porque no pueden o porque no tienen medios. Algunos de ellos no tienen internet o bien tienen un móvil para los cuatro de la familia. Entonces, no es lo mismo alguien que te entrega los deberes en un doc que alguien que tú ves que le está pegando pantallazos a un generador de textos del móvily así te va entregando los ejercicios. Con esta situación te das cuenta cómo en función de la clase social, el alumnado tiene unas oportunidades u otras. Veo ahí una concepción muy aristocrática de la educación. Esto es preocupante en términos de equidad, de justicia social y muy preocupante en términos de desigualdades educativas en el futuro. (Docente 4)
\end{abstract}

Zubillaga y Gortazar (2020) exponen que el derecho a la educación se está viendo amenazado en una situación en la que el grueso de los procesos de enseñanza-aprendizaje pasan por la red, debido a que los hogares situados en los quintiles más pobres de la población no cuentan con ningún ordenador o solo uno por familia para seguir la actividad docente. Es una situación que agrava los procesos previos de segregación escolar por factores socioeconómicos en el contexto español (Murillo y Martínez-Garrido, 2018). Cuestiones que también se recogen en el trabajo de Trujillo-Sáez y otros (2020) y que llevan al 45,3\% del profesorado a considerar que se deberían adoptar medidas de apertura y uso de los centros educativos para estudiantes de sectores más desfavorecidos ante eventuales escenarios donde pueda verse afectada la educación presencial. También notable la consideración del 48,4\% de los docentes que reclaman mayor autonomía para adaptar el currículum al contexto del alumnado con la finalidad de paliar las brechas originadas por el cierre de centros.

\title{
3.2. El rol de la administración educativa en la crisis: cuestionamiento docente, tensio- nes emocionales y debilitamiento de la profesionalidad
}

La crisis producida por el COVID-19 se ha presentado como la enésima muestra del cuestionamiento permanente que vive el profesorado en diferentes latitudes geográficas. Son unánimes las muestras de hartazgo, hastío y malestar con la administración educativa por las diferentes dificultades experimentadas durante la educación online. En la mayoría de las narrativas es frecuente expresar el cansancio o la quemazón que produce el trabajo docente, más aún, cuando se refiere a la situación provocada por la crisis sanitaria:

Esta profesión quema ya de por sí. Imagínate con todo esto que estamos viviendo. Es hartazgo, es descreimiento, es un qué me voy a encontrar hoy cruzando los dedos para que no salga nada nuevo. Quema, no me gusta decir esto, pero hay días que te sientes realmente sin fuerzas. (Docente 8)

Ya desde principios de siglo se aborda el burnout para poner de manifiesto las tensiones emocionales, también físicas, que sufre el profesorado en las distintas esferas de su trabajo (Bolívar, 2006; Esteras et al., 2019). El desarrollo de una ocupación es un aspecto fundamental sobre el que la persona encuentra un sentido de propósito, pertenencia, satisfacción e identidad profesional (Hendrikx, 2019). En consecuencia, cuando se producen fuertes reestructuraciones en las condiciones laborales, como las producidas en educación por la pandemia, sin contar con los actores que ejecutan y desarrollan la legislación, los cambios se convierten en fuente de estrés, ansiedad, depresión y otros trastornos de salud mental (Skinner et al., 2019). En este caso, el trabajo de campo ha detectado un mayoritario sentir de vulnerabilidad percibido ante la ausencia de apoyo recibido por la administración.

Esta situación está siendo muy difícil, tú estarás notando la vehemencia en mis palabras, me he sentido muy violentado por parte de la administración cuando llegó la circular del 2 de abril de 2020 forzándonos a los profesores a una modificación de las programaciones didácticas con la que está cayendo. Se me está pidiendo que atienda a una serie de responsabili- 
dades en unas circunstancias que exceden de nuestra labor. La administración hace un daño terrible. Es una dejación, una falta de apoyo, un esconderse en los peores momentos, brutal. La gente está perdiendo familiares, estamos viviendo una situación absolutamente trágica y nos están forzando al papeleo. (Docente 12)

El malestar docente, sin embargo, no es una cuestión emergente derivada de la crisis sanitaria. Al contrario, ha sido una realidad ampliamente abordada en el contexto español, sirva como ejemplo el reiteradamente citado trabajo de Esteve (1994). No obstante, sí es interesante comprobar cómo diversas realidades, a veces difusas e indeterminadas, terminan articulándose de manera cíclica en conflictos profesionales del colectivo docente que profundizan en su malestar. La novedad, más allá de la crisis producida por el COVID-19, radica en las formas que el profesorado tiene de gestionar la vulnerabilidad percibida. Así, en el contexto posmoderno, las problemáticas que afronta el docente deben ser asumidas mediante elecciones individuales que implican eventuales momentos de riesgo en la vida del profesorado. Ya se reflejaba, en la obra del citado autor, que, en un espacio social marcado por una experiencia permanente de demandas volátiles, el profesorado se encuentra de manera persistente sumido en la incertidumbre, la inestabilidad y la ambivalencia. El escenario del trabajo del profesorado ha cambiado en el contexto político dominado por la lógica neoliberal. La individualización ha obligado al profesorado a construir su vida profesional desde la inseguridad que implica lo que Dubet (2006) entendió como desinstitucionalización. La identidad profesional y la profesionalidad docente, ambas determinadas por relaciones simbióticas, ya no vienen condicionadas por un marco institucional estable, la institución escolar, sino que el sujeto se ve impelido a construirse lejos del predominio de la estructura (Bolívar, 2006). Estas cuestiones problemáticas se han afianzado con motivo del COVID-19 y han generado en el profesorado un sentimiento de orfandad institucional no vivido hasta el momento.

\begin{abstract}
¿Cuántas circulares han salido desde que empezó el confinamiento diciendo qué tenemos que hacer pero nadie dice cómo vamos a evaluar? Es una incertidumbre permanente, vivimos en la cuerda floja. (Docente 7)

Cuando volvamos a las aulas tenemos que ser los profesores los que controlemos las medidas de seguridad para que no haya un rebrote de la pandemia. ¿Cómo voy a hacer yo eso? Si a mí no me bajan la ratio y me hacen meter a 33 personas en un aula. Si no hay una voluntad política de invertir más dinero, no se va a conseguir que se reduzca o minimice el riesgo de pandemia. ¿Te das cuenta? Soy yo, nada más que yo. Todo lo tiene que hacer el profesor. (Docente 11)
\end{abstract}

El profesorado se percibe como un instrumento de la administración, un actor poco considerado en términos académicos y que, en distintas situaciones durante la crisis sanitaria, se siente utilizado para soslayar las deficiencias del sistema educativo ante la magnitud de problemas derivados de la educación remota. Una parte del profesorado lamenta trabajar con una mirada cortoplacista y limitada que no tiene en cuenta las necesidades del alumnado:

Durante el confinamiento la respuesta de la administración ha sido como un "ya te las apa-
ñarás" y aquí la gente en vez de buscar soluciones profundas, parece ser que lo importante es
cubrir el expediente, así se nos esté cayendo el mundo encima. Primero los docentes y luego
los adolescentes. A nosotros la administración nos echa una serie de cargasy de responsabili-
dades, en una situación absolutamente jodida y complicada y nosotros, por tal de no recibir
represalias, machacamos a los adolescentes a deberes. Es terrible. (Docente 12)

Se evidencia un intento permanente de individualizar la responsabilidad del éxito del plan educativo previsto sobre el profesorado. Los relatos manifiestan que esto provoca tensiones e inquietud al tiempo que genera desequilibrios en los elementos que conforman su identidad profesional. Se experimentan conflictos subjetivos entre las demandas exógenas y aquello que el profesorado considera más importante atendiendo a la excepcionalidad del momento. Una relación vertical que no considera la multiplicidad de factores que intervienen en los procesos educativos y que se basa en la presión individual sobre el profesorado no solo tiene efectos negativos en términos de rendimiento para el alumnado, sino que deteriora el sentido de responsabilidad profesional, compromiso y empobrece su desarrollo profesional (Sugrue y Mertkan, 2017). Pese a ello, el profesorado expresa haberse volcado para mitigar los efectos de 
la pandemia sobre el alumnado, aunque esto haya supuesto estados de fuerte carga física y emocional para responder a los desafíos encontrados:

La primera semana fue tremenda, el nivel de presión y exigencia autoimpuesto, centrándose única y exclusivamente, como si nos hubiéramos puesto unas orejeras grandes para adelante y solamente viéramos: "tengo que seguir con las clases, tengo que seguir con las clases", sin pararnos a pensar si este niño tiene conexión a internet o sabe usar las TIC. El problema era que nosotros nos sentíamos responsables si los alumnos no se conectaban, si entregaban las tareas... (Docente 11)

Se trata de asumir una "auto-responsabilización” coherente con la progresiva promulgación de reformas que resitúan el rol de las administraciones educativas y depositan sobre el profesorado el cometido de los éxitos educativos definidos sin su participación. Así, el movimiento global de reformas educativas, siguiendo estudios como el desarrollado por (Bailey, 2015), ha situado al profesorado en el centro de los debates y ha promovido que sientan permanentemente la necesidad de mostrarse flexibles, resolutivos y competentes en contextos de incertidumbre y ambivalencia. Cuando esto no se cumple pueden llegar a producirse emociones de irresponsabilidad, temor y culpabilidad. Así, la forzada incorporación de la digitalización de la docencia con la consiguiente adaptación curricular o la atención al alumnado con necesidades educativas especiales, entre otras cuestiones, han generado dificultades tanto en la esfera personal como profesional que han aumentado las tensiones emocionales.

Yo tengo una situación personal y familiar difícil. En casa tengo problemas, tengo hijos, tengo un hijo con un problema de salud grave... imagínate cómo es tener que cuidar de ellos al tiempo que contestas correos o haces tres veces el mismo trámite burocrático... (Docente 15)

Me duele que la administración siempre me ponga en duda porque es desconfiar de la labor que hacemos. Si hay muchos suspensos, ¿qué estará haciendo el profesor para que haya tantos? Si hay muchos aprobados, ¿qué estará haciendo el profesor? Estoy muy cansada. Esta es una profesión muy atacada. Se nos culpabiliza de todo. (Docente 8)

$\mathrm{Al}$ contrario de las propuestas que diluían el papel de las emociones en las tareas docentes o las consideraban residuales, lo cierto es que las experiencias emocionales del profesorado se han demostrado fundamentales tanto en la relación persona-profesión como en el éxito educativo (Kelchtermans y Piot, 2013). Un éxito que, más allá de considerar la mejora de los rendimientos académicos, se ha revelado imprescindible en dimensiones relacionadas con el sentido colectivo del profesorado, con la confianza entre docentes y el desarrollo de una responsabilidad colectiva y horizontal en los quehaceres diarios de los centros (Berkovich y Eyal, 2015). Por ello, es urgente atender las narrativas que evidencian emociones de tristeza o frustración que deterioran la práctica docente y parecen encubrir, como alertaban Bolívar y otros (2014), un desequilibrio en los elementos que configuran la identidad profesional y determinan su profesionalidad.

Lo que estamos viviendo con el teletrabajo es un auténtico delirio. Yo me siento observaday agobiada. La sensación, hablando con los profesores, es de desamparo, de tristeza y frustración. (Docente 15)

Que a mí me consideren, como hizo el presidente de Castilla La Mancha o el Vicepresidente de la Junta de Andalucía cuando eclosionó el coronavirus que "los profesores quieren 15 días de vacaciones". Es una pena que todo lo que se ve de mi trabajo sean las vacaciones que tengo. Me produce una tristeza y una frustración impresionante. (Docente 8)

Ya exponía Fullan (2002) que una de las razones principales por las que las reformas fracasan se debe a la distancia entre los policy makers y el conjunto de profesionales que las ejecutan. Lejos de incorporar las propuestas y experiencias docentes en el debate político de la educación durante la pandemia, se comprueba que las medidas se dirigen en el sentido opuesto a las demandadas. Sirva como ejemplo la burocratización que sufre el profesorado y que, entre otras cuestiones, impide centrarse en las necesidades coyunturales del alumnado durante la educación a distancia:

Creíamos que, por una vez, se cambiarían las prioridades, que la epidemia pondría el foco en las necesidades de aprendizaje del alumnado. Pero no. Incluso tenemos más burocracia: más informes, más actas... Las directrices de la administración es que guardemos copia de correos, 


\section{de clases online, de documentos, de las actividades del alumnado. Creo que esto empobrece el propio concepto de educación. (Docente 5)}

Paradójicamente, las reformas basadas en el paradigma de la NGP prometían terminar con la burocratización que denuncia el profesorado y que es sentida como un obstáculo para su desarrollo profesional. Al contrario, cuando estas prácticas se han perpetuado en la mayoría de sistemas educativos (Verger y Normand, 2015), los docentes confiesan tener que atender con asiduidad a la cumplimentación de documentos, informes, reseñas y rúbricas que más que ser útiles como instrumentos para facilitar la comunicación con la administración o con las familias, se conciben como tecnologías de control de su práctica que manifiestan una sentida desconfianza sobre su trabajo.

Hay un problema: necesitamos una legislación que confíe mucho más en los docentes y que no sobrelegisle para cargarnos de historias. Que no piensen que porque nos den menos contenidos vamos a hacer menos. Al contrario, que nos den cierta libertad. Este es uno de los principales problemas de la carga burocrática, que se está fiscalizando el trabajo del profesorado. Eso hace que se genere una desconfianza por parte de él mismo con respecto a las instituciones que lo gobiernan. (Docente 10)

Cuando la legislación no promueve la confianza del profesor hay una pérdida porque no se genera ese reconocimiento, que no es reconocimiento del ego, sino un reconocimiento social justo. Entonces quienes generan esas normas deberían haber pasado por centros educativosy haber sentido en su propia piel esa vulnerabilidad y esa duda permanente sobre las medidas que nos rodean. Ese es el verdadero virus que estamos viviendo en educación, el virus de la desconfianza. (Docente 2)

Pero no solo las demandas burocráticas descubren la sensación de vulnerabilidad vivida por el profesorado. En las narrativas puede inducirse que esto solo es un aspecto, aunque quizá el más importante, de una realidad poliédrica. El reconocimiento social, la pérdida de prestigio o el cuestionamiento permanente de su práctica son, también, aspectos recurrentes en los discursos docentes. Esta tampoco es una cuestión relevante por la novedad semántica de los relatos, sino por los remanentes históricos que suscita la cuestión del reconocimiento de la labor docente ante una situación sin precedentes en la historia reciente. Véanse para el caso español investigaciones como la de Bolívar (2006), donde se señalaba que la ausencia de percepción de reconocimiento podría deberse a cuestiones intangibles como la falta de implicación de las familias en las tareas educativas. También Fernández-Enguita (2006) que aludía a una actitud victimista por parte del profesorado que podría terminar contaminando la opinión pública sobre los docentes. Sin intención de hipotetizar las causas, la percepción de falta de reconocimiento se vuelve a proyectar actuando como desencadenante la crisis educativa consecuente del COVID-19.

Nadie está viendo la labor de la docencia, nadie nos va a hacer mención. La mención solo viene porque los niños están en la casa y los tienen que tener los padres, somos guarderías que tenemos al alumnado. Es muy triste. Yo no quiero que me aplaudan, no es eso, es poner cada cosa en su sitio. (Docente 8)

Con la docencia en casa resulta que todo el mundo sabe más de educación que tú. En las redes sociales, ¿cuántas opiniones has leído sobre si hay que trabajar en casa o no, si hay que trabajar de esta forma o no? Es tremendo el desprestigio que tenemos los docentes. (Docente 7)

Ante esta percepción, la mayor parte del profesorado emplea una narrativa que reivindica el rol del docente en el plano social y académico, aunque no se ha detectado un patrón discursivo que sirva para mostrar una línea crítica compartida. Entre otras cuestiones porque en distintas ocasiones el profesorado no se reconoce como profesional y apela al oficio o la vocación para referirse a su cometido laboral. Es una cuestión persistente en análisis sociológicos que cuestionan la docencia como profesión, semiprofesión u oficio (Tardif, 2013). Tampoco puede abstraerse del análisis la persistencia de una subjetivación dominada por la lógica neoliberal que invita al profesorado a cuestionarse permanentemente el significado de ser un (buen) trabajador de la educación, al tiempo que construye un modelo determinado de profesional competente y con éxito (Buchanan, 2015). Por ello, pese a los posicionamientos críticos que se muestran en la mayoría de casos, una parte del profesorado termina adoptando prácticas que les proporcionan seguridad en el corto plazo. En la mayoría de ocasiones coincidiendo con los requerimientos a los que son 
impelidos, y así se refleja en narrativas que destacan por su motivación contingente, técnica y finalista (Bailey, 2014):

Lo que más me preocupa es seguir manteniendo la ilusión. Ser crítico pero también resiliente. En estos momentos es muy importante reinventarse, innovar y habrá que buscar la fórmula de llegar al alumno. Esa responsabilidad es mía. (Docente 13)

Yo formo al profesorado y al final es, como les digo, hay que ser resilientes. Hay que adaptarse constantemente para responder de la mejor manera al alumnado. Ya está, al final cada uno trabaja, los profesores tenemos una capacidad de resiliencia que lo flipas y al final el alumno no se ve perjudicado. (Docente 18)

En otros estudios (Molina-Pérez y Luengo, 2020) se ha realizado un análisis crítico sobre la reciente evocación a aspectos referidos a la gestión de las emociones para que no se conviertan en fuentes de conflicto profesional relacionadas con el estrés o la insatisfacción profesional. En la mencionada investigación se presenta la noción de resiliencia como una capacidad sobre la que el profesorado debe de reconstruir su identidad profesional para no sufrir mayor desgaste en entornos de vulnerabilidad y presión. Y es que, pese a la excepcionalidad de la situación provocada por el COVID-19, las lógicas de cuantificación, datificación y comparación no se desvanecen. La estandarización, la evaluación y la configuración de cuasimercados educativos lleva a los centros a focalizarse sobre los resultados académicos para no perder alumnado, líneas o servicios que puedan debilitar su posición en el entorno competitivo de escolarización (Olmedo y Wilkins, 2014). En este contexto, el profesorado denuncia cómo la administración presiona para salvar los resultados académicos del curso escolar, priorizando esta cuestión sobre el resto.

Para mí tiene una lectura negativa y de presión porque hay muchisimas exigenciasy muchisima presión para que no dejemos de trabajar los contenidos cuando, realmente, estamos viviendo unas circunstancias muy excepcionales donde igual tendríamos que estar trabajando otras cuestiones más humanas y menos los contenidos. (Docente 6)

Yo estoy muy presionado, sobre todo con esto del teletrabajo, de buscar la forma de trabajar con ellos. Es muy difícil, frustra mucho, es una gana de intentar continuamente hacer las cosas en condiciones porque después tus resultados nadie va a tener en cuenta que tú has hecho esta actividad, esta otra, o si le has dedicado más tiempo o menos tiempo, lo único que trasciende de tu trabajo de puertas afuera, no es lo que has trabajado o cómo, sino los resultados que has obtenido. (Docente 7)

\section{Reflexiones finales}

El cierre de los centros educativos con motivo del COVID-19 ha puesto de manifiesto la precariedad de las infraestructuras digitales de los centros y las dificultades del profesorado para integrar las TIC en sus programaciones con la celeridad requerida. Los relatos sobre las infraestructuras digitales, los recursos online, las pedagogías TIC y las competencias digitales muestran que la educación remota "improvisada" ha evidenciado debilidades como el desigual acceso a recursos tecnológicos entre el alumnado más vulnerable, las diferencias en el seguimiento de una parte del alumnado, la brecha digital, la precariedad tecnológica del sistema educativo y la consecuente falta de habituación de una parte del profesorado a la utilización de herramientas TIC. Los docentes, en consecuencia, han respondido dedicando más horas de su tiempo y asumiendo responsabilidades que hubieran correspondido a las administraciones educativas y decisores políticos. Por ello, cuando una parte del debate público acoge la digitalización como la respuesta de futuro más certera, el profesorado entrevistado ha mostrado mayoritariamente posicionamientos escépticos y la necesidad de recuperar la docencia presencial, espacio que valoran como parte esencial de su tarea laboral (Hargreaves, 1996).

Esto ha puesto el foco de atención en las condiciones en las que se desarrollarán los próximos cursos. La mayor parte del profesorado alude a preocupaciones referidas, fundamentalmente, a la digitalización de los procesos educativos, la disponibilidad de recursos digitales y el seguimiento del alumnado más vulnerable de la docencia híbrida (dentro y fuera del aula), como así se refleja también en el trabajo de Trujillo-Sáez et al. (2020) para el curso 2020/2021. Y es que, como recogen los relatos, la crisis sanitaria 
está profundizando en las ya acuciantes desigualdades educativas previas, los procesos de segregación y el cuestionamiento de un modelo socialmente justo (Murillo y Martínez-Garrido, 2018). También es destacable que, en algunos casos, el profesorado entrevistado ha revelado cómo la carencia de recursos digitales y la falta de habituación en el uso de las TIC han llevado a la utilización de dispositivos y plataformas digitales privadas. Se observa cómo esta cuestión genera recelo en una parte del profesorado en un contexto donde la industria educativa digital comienza a introducirse en los sistemas educativos públicos mediante modelos de digitalización que cuestionan el rol del profesorado en el aula (Williamson, 2017).

Si relevante es comprender cómo se ha desarrollado la rápida conversión hacia la digitalización en un contexto marcado por la improvisación coyuntural, la precariedad de infraestructuras y la falta de apoyo técnico-pedagógico, urge prestar atención a la experiencia emocional vivida por el profesorado (Berkovich y Eyal, 2015). Toda reforma o proceso de cambio acelerado en la lógica del trabajo tiene un impacto sobre las emociones del profesorado que determina el éxito de la práctica docente (Day, 2018). La vivencia emocional se ha descubierto fundamental para entender cómo los docentes negocian las directrices generadas fuera de su ámbito de competencia y que condicionan su profesionalidad. En la mayoría de ocasiones suele producirse un desequilibrio o crisis en los elementos que configuran la identidad profesional. Así, en reiteradas ocasiones los docentes sienten cuestionada su eficacia profesional por las condiciones y competencias que conlleva el uso de las TIC. Al mismo tiempo manifiestan no sentirse respaldados, apoyados ni reconocidos por la administración educativa. En este caso, es necesario atender a la sensación de orfandad institucional que manifiesta el profesorado. En la totalidad de narrativas analizadas se denuncia una percepción de abandono y dejación de la administración educativa andaluza. Se señala en sus relatos la distancia entre lo que se les demanda y su vivencia cotidiana, al tiempo que asumen una auto-responsabilización en la trayectoria académica del alumnado. Este vacío de apoyo o reconocimiento tampoco lo encuentra el profesorado en otros agentes sociales. La mayor parte de docentes expresan no sentirse valorados socialmente, cuando no cuestionados o despojados de prestigio social. Podría inducirse, de acuerdo con las narrativas, que una parte del profesorado ha asumido vivir permanentemente cuestionado y que, en algunas ocasiones, esto se asume como una oportunidad para demostrar su vocación o compromiso con el logro de los objetivos educativos. La mayor parte del profesorado emplea narrativas que reivindican la resiliencia para reponerse a cualquier dificultad que se presente como potencial del colectivo (Molina-Pérez y Luengo, 2020). La actitud y la gestión emocional se convierten en cuestiones clave que comienzan a impregnar la formación, los discursos y las agendas políticas para responder a la insatisfacción que, desde hace décadas, manifiesta el profesorado (Esteve, 1994).

Llegados hasta aquí, es necesario reflexionar, más que concluir, sobre las implicaciones que el COVID-19 dibuja en la educación. La falta de certezas condiciona la planificación educativa para los siguientes cursos al tiempo que las administraciones educativas diseñan planes ambiguos sin la participación del profesorado. Se plantean modelos híbridos de enseñanza-aprendizaje, reducción de grupos-clase, días alternos de asistencia por parte del alumnado y medidas de higiene y seguridad sanitaria. No parece lógico excluir al profesorado del debate político o la investigación académica. Al mismo tiempo, es necesario poner voz a los trabajos cuantitativos que recogen las percepciones de un amplio número de docentes. Es evidente que los estudios de corte cualitativo tienen un notable interés en estos momentos y es necesario desarrollar investigaciones que mapeen narrativas del profesorado e identifiquen las ambivalencias, las incertidumbres y las fracturas ocurridas durante la educación remota. Otra línea de trabajo fundamental se encuentra en los estudios cualitativos comparados para asegurar la calidad de la investigación interpretativa y la finalidad de "transferibilidad" de las aportaciones dependientes del contexto de estudio. La profundización en esta línea de investigación servirá también para resolver algunas limitaciones que presenta el trabajo. Haber realizado las entrevistas durante los momentos más convulsos e inciertos del Estado de alarma puede haber condicionado la rotundidad de las manifestaciones recogidas. Será de interés comprobar cómo evolucionan las percepciones del profesorado en los sucesivos meses. Por otro lado, la realización de las entrevistas por medio de aplicaciones de videollamada puede limitar la capacidad de recoger aspectos de interés para todo proceso de investigación hermenéutico (expresiones, movimientos, silencios o lenguaje no verbal, entre otros). El contacto con el profesorado y el trabajo etnográfico será fundamental para profundizar en estas y otras preguntas de investigación que se consideran esenciales en los próximos tiempos. 


\section{Referencias}

Bailey, G. (2014). Accountability and the rise of play safe pedagogical practices. Education Training, 56(7), 663-674. https://doi.org/10.1108/ET-07-2014-0081

Bailey, P. L. (2015). Consultants of conduct: New actors, new knowledges and new resilient subjectivities in the governing of the teacher. Journal of Educational Administration and History, 47(3), 232-250. https://doi.org/10.1080/00220620.2015.1038696

Ball, S. J., Junemann, C. y Santori, D. (2017). Edu.net. Globalisation and Education Policy Mobility. Routledge.

Berkovich, I. y Eyal, O. (2015). Educational leaders and emotions: An international review of empirical evidence 1992-2012. Review of Educational Research, 85(1), 129-167. https://doi.org/10.3102/0034654314550046

Bolívar, A. (2006). La identidad profesional del profesorado de Secundaria. Crisis y reconstrucción. Aljibe.

Bolívar, A., Domingo, J. y Pérez-García, P. (2014). Crisis and reconstruction of teachers' professional identity: The case of secondary school teachers in Spain. The Open Sports Sciences Journal, 7, 106-112. https://doi.org/ff10.2174/1875399X01407010106ff

Buchanan, R. (2015). Teacher identity and agency in an era of accountability. Teachers and Teaching, 21(6), 700-719. https://doi.org/10.1080/13540602.2015.1044329

Bueno, E., Salmador, M. P. y Merino, C. (2008). Génesis, concepto y desarrollo del capital intelectual en la economía del conocimiento: Una reflexión sobre el modelo Intellectus y sus aplicaciones. Estudios de Economía Aplicada, 26(2), 43-63.

Charmaz, K. (2004). Grounded theory: Objectivist and constructivist methods. En R. M. Emerson (Ed.), Contemporary field research (pp. 109-126). Little, Brown and Company.

Comisión Europea. (2019). Second survey of schools: ICT in education. Comisión Europea.

Cornet-Calveras, A. (2005). Nuevos planteamientos didácticos: ¿Al innovar en docencia, mejoramos el aprendizaje? Educación Médica, 8(1), 18-21.

Day, C. (2018). Professional identity matters: Agency, emotions, and resilience. En P. Schutz, J. Hong y D. Cross (Eds.), Research on teacher identity (pp. 61-70). Springer._https://doi.org/10.1007/978-3-319-93836-3_6

Dubet, F. (2006). El declive de la institución: Profesiones, sujetos e individuos en la modernidad. Editorial Gedisa.

Esteras, J., Chorot, P. y Sandín, B. (2019). Sintomatología física y mental asociada al síndrome de burnout en los profesionales de la enseñanza. Revista de Psicopatología y Psicología Clínica, 24(1), 29-37.

https://doi.org/10.5944/rppc.23776

Esteve, J. M. (1994). El malestar docente. Paidós.

Fernández-Enguita, M. (2006). Pero... ¿qué querrán? el estatus del profesorado y el tópico del reconocimiento. Cuadernos de Pedagogía, 353, 80-85.

Fullan, M. (2002). Los nuevos significados del cambio en la educación. Octaedro.

Giddens, A. (1995). Los contornos de la modernidad reciente. Modernidad e identidad del yo. El yo y la sociedad en la época contemporánea. Editorial Península.

Gispert-Pellicer, E. (1997). La moda tecnológica en la educación: los peligros de un espejismo. Pixel-Bit. Revista de medios y educación, 9, 81-92.

Glaser, B. y Strauss, A. (1967). The discovery of grounded theory. Aldine Publishing.

Hargreaves, A. (1996). Profesorado, cultura y postmodernidad: Cambian los tiempos, cambia el profesorado. Morata.

Hendrikx, W. (2019). What we should do vs what we do: teachers' professional identity in a context of managerial reform. Educational Studies, 46, 607-623. https://doi.org/10.1080/03055698.2019.1620694

Hinojo-Lucena, F. J., Aznar, I. y Romero-Rodríguez, J. M. (2020). Mobile learning en las diferentes etapas educativas. Una revisión bibliométrica de la producción científica en Scopus (2007-2017). Revista Fuentes, 22(1), 37-52. https://doi.org/10.12795/revistafuentes.2020.v22.11.04 
Kelchtermans, G. y Piot, L. (2013). Living the Janus head: Conceptualizing leaders and leadership in schools in the 21st Century. En M. A. Flores (Ed.), Back to the future (pp. 93-114). Sense Publishers.

https://doi.org/10.1007/978-94-6209-240-2_6

Krueger, R. A. y Casey, M. A. (2009). Focus groups: A practical guide for applied research. Sage Publications.

Luengo, F. y Manso, J. (2020). Informe de investigación Covid19. Voces de docentes y familias. Proyecto Atlántica. http:// www.proyectoatlantida.eu/wordpress/educacion-con-las-escuelas-cerradas-voces-de-familias-y-profesorado-sobre-la-educacion-durante-el-confinamiento

Molina-Pérez, J. y Luengo, J. (2020). Reconstrucciones “resilientes” de la identidad profesional del profesorado: Endoprivatización y cultura performativa en Andalucía (España). REICE. Revista Iberoamericana sobre Calidad, Eficacia y Cambio en Educación, 18(2), 57-75._https://doi.org/10.15366/reice2020.18.2.003

Murillo, F. J. y Martínez-Garrido, C. (2018). Magnitud de la segregación escolar por nivel socioeconómico en España y sus Comunidades Autónomas y comparación con los países de la Unión Europea. RASE. Revista de Sociología de la Educación, 11(1), 37-58. https://doi.org/10.7203/RASE.11.1.10129

Noy, C. (2008) Sampling knowledge: The hermeneutics of snowball sampling in qualitative research. Journal of Social Research Methodology, 11(4), 327-344._https://doi.org/10.1080/13645570701401305

Olmedo, A. y Wilkins, A. (2014). Gobernando a través de los padres y madres: Política educativa y construcción de subjetividades neoliberales en Inglaterra. Profesorado. Revista de Curriculum y de Formación del Profesorado, 18(2), 99-116.

Saura, G. (2018). Saving the world through neoliberalism: Philanthropic policy networks in the context of Spanish education. Critical Studies in Education, 59(3), 279-296. https://doi.org/10.1080/17508487.2016.1194302

Sennett, R. (2006). La cultura del nuevo capitalismo. Anagrama.

Skinner, B., Leavey, G. y Rothi, D. (2019). Managerialism and teacher professional identity: impact on well-being among teachers in the UK. Educational Review, 73, art 1._https://doi.org/10.1080/00131911.2018.1556205

Springer, S. (2010). Neoliberalism and geography: Expansions, variegations, formations. Geography Compass, 4(8), 1025-1038. https://doi.org/10.1111/j.1749-8198.2010.00358.x

Sugrue, C. y Mertkan, S. (2017). Professional responsibility, accountability and performativity among teachers: the leavening influence of CPD? Teachers and Teaching, 23(2), 171-190._https://doi.org/10.1080/13540602.2016.1203771

Tardif, M. (2013). El oficio docente en la actualidad. Perspectivas internacionales y desafíos a futuro. En M. Poggi (Coord.), Políticas docentes. Formación, trabajo y desarrollo profesional (pp. 19-44). UNESCO.

Tett, L. y Hamilton, M. (2019). Resisting neoliberalism in education: Local, national and transnational perspectives. Policy Press.

Trujillo-Sáez, F., Fernández-Navas, M., Montes-Rodríguez, R., Segura-Robles, A., Alaminos-Romero, F. J. y Postigo-Fuentes, A. Y. (2020). Panorama de la educación en España tras la pandemia de COVID-19. Fad. https://doi.org/10.5281/zenodo-3878844

UNESCO (2020). El grupo de trabajo de maestros llama a apoyar a 63 millones de maestros afectados por la crisis de COVID-19. UNESCO.

Verger, A. y Normand, R. (2015). Nueva gestión pública y educación: Elementos teóricos y conceptuales para el estudio de un modelo de reforma educativa global. Educação \& Sociedade, 36(132), 599-622.

https://doi.org/10.1590/ES0101-73302015152799

Williamson, B. (2017). Big data in education: The digital future of learning, policy and practice. Sage.

Wengraf, T. (2012). Qualitative research interviewing. Sage Publications.

Yanes-González, J. Y. G. Y. y Area-Moreira, M. A. (1998). El final de las certezas. La formación del profesorado ante la cultura digital. Píxel-Bit. Revista de Medios y Educación, 10, 25-36

Zubillaga, A. y Gortazar, L. (2020). Covid 19 y educación I: Problemas, respuestas y escenarios. Fundación Cotec. 


\section{Breve CV de los/as autores/as}

\section{Javier Molina-Pérez}

Contratado predoctoral FPU (Formación de Profesorado Universitario) en el Departamento de Pedagogía de la Universidad de Granada. Graduado en Pedagogía y Máster en Investigación, Desarrollo Social e Intervención Socioeducativa por la misma Universidad. Visiting academic en School of Education (University of Bristol). Las líneas de investigación se centran en el ámbito de la política educativa y la profesión docente. Las contribuciones abordan el análisis de la Identidad Profesional del profesorado en el contexto de la reforma política neoliberal, los cambios en la profesionalidad docente y las dinámicas de privatización en educación. Email: javimp@ugr.es

ORCID ID: https://orcid.org/0000-0001-6751-2199

\section{Cristina Pulido-Montes}

Graduada en Pedagogía, Máster en Política, Gestión y Dirección de Organizaciones Educativas y Doctora en Educación Sobresaliente Cum Laude por la Universidad de Valencia. Contratada predoctoral FPU (Formación de Profesorado Universitario) del Departamento de Educación Comparada e Historia de la Educación de la Universidad de Valencia (2015/2019) y Visiting Research Scholar en el Institute of Education of London de la University College of London (2016/2017). Sus líneas de investigación son los procesos de neoliberalización, recontextualización de políticas educativas y procesos "de", "en” y privatización híbrida de la educación en países desarrollados y en desarrollo. Email: cristina.pulido@uv.es

ORCID ID: https://orcid.org/0000-0003-1087-461X 